\title{
Characteristics of clinical trial websites: information distribution between ClinicalTrials.gov and 13 primary registries in the WHO registry network
}

\author{
Daisuke Ogino ${ }^{1}$, Kunihiko Takahashi ${ }^{1,2}$ and Hajime Sato ${ }^{1 *}$
}

\begin{abstract}
Background: It is well known that information about clinical trials is not easily accessible by the public. In Japan, clinical trial information can be accessed by the general public through online registries; however, many people find these registries difficult to use. To improve current clinical trial registries, we propose that combining them with clinical information phrased in lay terms would be beneficial to other interested professionals such as journalists and clinicians, as well as the general public. Therefore, this study aimed to examine the current pattern of distribution of clinical trial information from the primary World Health Organization (WHO) registries. Based on the results of this assessment, we then aimed to build and evaluate a prototype of the Japan Primary Registries Network (JPRN) portal that would be easily accessible to patients and the public, while still remaining useful for professionals.
\end{abstract}

Methods: We assessed a total of 14 primary clinical trial registries listed on the WHO International Clinical Trials Registry Platform between January and February 2013. Website content was accessed and checked against a series of items that looked at usability, communication, design and accessibility of the sites. We excluded registries that were not active or were not on the approved WHO registry list at the time of our assessment. We also examined only the English versions of the websites as native-language registries may offer more functionality or different content than the English version of the same website.

Results: All registries examined had a function allowing users to search the registry data and that displayed the related information from the search, including the clinical trial registration data. However, few websites were found to be user-friendly, and there was little integration with social media.

Conclusions: We confirmed that there are few websites providing useful clinical trial information to patients and their families. However, information gleaned from some of the more advanced online registries could be used to improve the content and functionality of the JPRN portal.

Keywords: WHO International Clinical Trials Registry, Registry, Clinical trials, Website usability

\section{Background}

The Japan Primary Registries Network (JPRN) is maintained by the Ministry of Health, Labour and Welfare in Japan (MHLW) and the National Institute of Public Health, Japan, which hosts the Clinical Trials Search portal [1]. The network comprises three primary registries: the University Hospital Medical Information Network [2];

\footnotetext{
* Correspondence: hsato@niph.go.jp

1 Department of Health Policy and Technology Assessment, National Institute of Public Health, 2-3-6 Minami, Wako, Saitama 351-0197, Japan

Full list of author information is available at the end of the article
}

the Japan Pharmaceutical Information Center's Clinical Trials Information [3] and Japan Medical Association's Center for Clinical Trials [4]. The JPRN portal was recognized as a World Health Organization (WHO) primary registry in 2008. It collects and manages clinical trial data in both Japanese and English. Several problems with the website have been pointed out by the clinical trial activation committee, including that patients found the portal difficult to use [5].

According to the 2012 Five-Year Clinical Trial Activation Plan proposed by the MHLW and the Ministry of 
Education, Culture, Sports, Science, and Technology, the goal is that patients and the public should be able to access the JPRN portal and learn from the clinical trial information stored within it, while researchers and clinicians can use the clinical trials information to help produce new innovations in Japanese medical treatment, such as new drugs [6]. Therefore, to improve the JPRN portal, we suggest that the current portal is combined with clear clinical information in lay terms to enhance the usability and understanding of clinical trials and other medical research (currently the portal does not focus exclusively on clinical trials, but also provides general medical information to the public) by the general public and any interested professionals [5,6]. We propose that sharing the challenges of providing information between three data providers and the government would provide cohesive benefits for the JPRN. It would be possible to carry out joint improvement activities such as system maintenance, data formatting and quality control of the registration data. This could improve the system, including the website, while maintaining coordination with the network of the primary registry. Modification of the present Japanese clinical trial search portal site would address users' requests for a more user-friendly and convenient website for all users, including patients and their families, medical professionals, pharmaceutical companies and researchers. Promoting participation in clinical trials and a greater understanding of clinical research would also be beneficial to the public [7]. Furthermore, an improvement in the quality of clinical trials, such as those investigating innovative new drugs, would be likely.

To determine the current pattern of distribution of clinical trial information from the WHO primary registries, an assessment needs to be conducted for each website. Based on the results of this assessment, a system prototype that could be easily accessed by patients and the general public and that would still be useful for medical professionals, could be built and evaluated against the goals proposed above.

\section{Methods}

The websites of 14 clinical trial databases were assessed between January and February 2013. ClinicalTrials.gov (CT.gov) [8] and 13 primary registries listed in the WHO International Clinical Trials Registry Platform (ICTRP) [9] were included in this study (Table 1). We evaluated each registry against a checklist comprising 16 items related to website content (Table 2), 18 items on navigation, search and whether the website could be used in multiple languages (hereafter, referred to as multilingualization; Table 3), and 19 items related to website function, communication, design and accessibility (Table 4). All 14 websites were assessed by a web designer and developer. The checklist was prepared by all authors following a
Table 1 List of websites assessed in this study

\begin{tabular}{|c|c|}
\hline $\begin{array}{l}\text { Nation or } \\
\text { region }\end{array}$ & Organization/URL \\
\hline \multirow[t]{2}{*}{ Japan } & Japan Primary Registries Network (JPRN) \\
\hline & http://rctportal.niph.go.jp/ \\
\hline \multirow[t]{2}{*}{ USA } & $\begin{array}{l}\text { ClinicalTrials.gov (a service of the US National Institutes } \\
\text { of Health) }\end{array}$ \\
\hline & http://www.clinicaltrials.gov/ \\
\hline \multirow{2}{*}{$\begin{array}{l}\text { Australia and } \\
\text { New Zealand }\end{array}$} & Australian New Zealand Clinical Trials Registry (ANZCTR) \\
\hline & http://www.anzctr.org.au/ \\
\hline \multirow[t]{2}{*}{ Brazil } & Brazilian Clinical Trials Registry (ReBec) \\
\hline & http://www.ensaiosclinicos.gov.br/ \\
\hline \multirow[t]{3}{*}{ China } & Chinese Clinical Trial Registry (ChiCTR) \\
\hline & http://chictr.clinicaltrialecrf.org/en/ \\
\hline & (http://www.chictr.org/en/) \\
\hline \multirow[t]{3}{*}{ South Korea } & Clinical Research Information Service (CRiS) \\
\hline & http://ncrc.cdc.go.kr/cris/en/use_guide/cris_introduce.jsp \\
\hline & (https://cris.nih.go.kr/cris/en/use_guide/cris_introduce.jsp) \\
\hline \multirow[t]{2}{*}{ Cuba } & Cuban Public Registry of Clinical Trials (RPCEC) \\
\hline & http://registroclinico.sld.cu/ \\
\hline \multirow[t]{2}{*}{ EU } & EU Clinical Trials Register (EU-CTR) \\
\hline & https://www.clinicaltrialsregister.eu/ \\
\hline \multirow[t]{2}{*}{ Germany } & German Clinical Trials Register (DRKS) \\
\hline & https://drks-neu.uniklinik-freiburg.de/drks_web/ \\
\hline \multirow[t]{2}{*}{ Iran } & Iranian Registry of Clinical Trials (IRCT) \\
\hline & http://www.irct.ir/ \\
\hline \multirow[t]{2}{*}{ UK } & $\begin{array}{l}\text { International Standard Randomised Controlled Trial } \\
\text { Number Register (ISRCTN) }\end{array}$ \\
\hline & http://www.isrctn.org/ \\
\hline \multirow[t]{2}{*}{ Netherlands } & Netherlands National Trial Register (NTR) \\
\hline & http://www.trialregister.nl/trialreg/index.asp \\
\hline \multirow[t]{2}{*}{ Pan Africa } & Pan African Clinical Trial Registry (PACTR) \\
\hline & http://www.pactr.org/ \\
\hline \multirow[t]{2}{*}{ Sri Lanka } & Sri Lanka Clinical Trials Registry (SLCTR) \\
\hline & http://www.slctr.lk/ \\
\hline
\end{tabular}

review of the literature. We focused on problems identified by the MHLW Clinical Trial Activation Committee [5] and the National Cancer Institute (NCI) International Clinical Trials Portal Website Usability Test Report [10].

The assessment results were analyzed to determine patterns in how clinical trial information was provided. We assessed only the English versions of the included registries (with the exception of the JPRN portal site, for which the Japanese version was assessed), as nativelanguage versions of these websites may offer more functions or different content than the English versions. With respect to institutional review board (IRB) information, because we only searched the English websites of each registry, it is possible that information was missed if it was included using terms other than 'IRB' or was written in the authors' native language. The IRB 
Table 2 Website content

\begin{tabular}{|c|c|c|c|c|c|c|c|c|c|c|c|c|c|c|}
\hline Assessment item & JPRN & CT.gov & ANZCTR & ReBec & ChiCTR & CRiS & RPCEC & EU CTR & DRKS & IRCT & ISRCTN & NTR & PACTR & SLCTR \\
\hline $\begin{array}{l}\text { Pages for each type of user, } \\
\text { such as patients and health } \\
\text { professionals }\end{array}$ & No & Partly & No & No & No & No & No & No & No & No & No & No & No & No \\
\hline $\begin{array}{l}\text { Content for each type of user, } \\
\text { such as patients, health } \\
\text { professionals and clients }\end{array}$ & No & Partly & No & No & No & No & No & No & No & No & No & No & No & No \\
\hline $\begin{array}{l}\text { Clinical trial information } \\
\text { pages (patient) }\end{array}$ & - & - & - & - & - & - & - & - & - & - & - & - & - & - \\
\hline $\begin{array}{l}\text { Clinical trial information } \\
\text { pages (health professional) }\end{array}$ & - & - & - & - & - & - & - & - & - & - & - & - & - & - \\
\hline $\begin{array}{l}\text { Information pages on } \\
\text { diseases (patient) }\end{array}$ & No & No & No & No & No & No & No & No & No & No & No & No & No & No \\
\hline $\begin{array}{l}\text { Information pages on } \\
\text { medicine and treatment } \\
\text { for diseases (patient) }\end{array}$ & No & No & No & No & No & No & No & No & No & No & No & No & No & No \\
\hline $\begin{array}{l}\text { Links to information on } \\
\text { diseases, drugs or treatments }\end{array}$ & No & No & No & No & No & No & No & No & No & No & No & No & No & No \\
\hline $\begin{array}{l}\text { List of ongoing clinical } \\
\text { trial information }\end{array}$ & Yes & Yes & Yes & Yes & Yes & Yes & Yes & Yes & Yes & Yes & Yes & Yes & Yes & Yes \\
\hline $\begin{array}{l}\text { Information on the institutional } \\
\text { review board (IRB) }\end{array}$ & No & Partly & No & No & No & No & No & No & Partly & No & No & No & No & Partly \\
\hline IRB information page (patient) & - & Partly & No & No & No & No & No & No & No & No & No & No & No & No \\
\hline $\begin{array}{l}\text { IRB information page (health } \\
\text { professional) }\end{array}$ & - & No & No & No & No & No & No & No & No & No & No & No & No & No \\
\hline Use of videos and images & No & No & No & No & No & No & No & No & No & No & No & No & No & No \\
\hline $\begin{array}{l}\text { Frequently asked questions } \\
\text { (patient) }\end{array}$ & Yes & Partly & No & No & Yes & No & No & Yes & Yes & Yes & No & No & Yes & Yes \\
\hline $\begin{array}{l}\text { Frequently asked questions } \\
\text { (health professional) }\end{array}$ & - & - & Yes & Yes & No & No & No & - & - & - & Yes & No & - & - \\
\hline Glossary (patient) & Yes & Yes & No & No & No & No & No & Yes & Yes & No & No & No & No & No \\
\hline Glossary (health professional) & - & - & No & No & No & No & No & - & - & No & - & No & No & No \\
\hline
\end{tabular}

'No' encompasses 'not provided', 'no description' and 'no distinction'. A dash (-) indicates that the response is summarized in the answer of another item or could not be evaluated.

information may also contain information that overlaps with other ethics committee information. This was a limitation here, in that we were not able to check in the native language of the registry whether the item had been provided. We excluded registries that were either not active or that were not on the WHO list of approved registries at the time of our assessment. We did not correspond with the administrators of any of the registries to clarify, supplement or verify the information extracted. The assessment was completed based on the information provided on each of the 14 registry websites.

\section{Results}

\section{Website content}

The CT.gov website contained content and parts of pages devoted to each type of user (laypeople and professionals such as clinicians, funders, journal editors, journalists, systematic reviewers and researchers), although the distinction was not always clear. None of the 14 websites had separate pages with information on clinical trial information, disease information, medicine and treatments for diseases, or links to similar information. All 14 websites had a list of ongoing clinical trial data. Eleven websites incorporated frequently asked questions, and four websites included a glossary (Table 2).

\section{Website multilingualization, navigation and search}

Regarding the use of multiple languages on the websites, organizations with a native language other than English were presumed to use multiple languages. Global navigation was one of the usability items assessed. Global navigation systems place page links onto the website homepage, and function as a shortcut to the content of the website. Global navigation can help users understand the complete scope of the website or their current position in the website. Breadcrumb navigation displays web pages within a hierarchy on the website. This display makes it easy to determine where the user is located within the website and 
Table 3 Website multilingualization, navigation and search

\begin{tabular}{|c|c|c|c|c|c|c|c|c|c|c|c|c|c|c|}
\hline Assessment item & JPRN & CT.gov & ANZCTR & ReBec & ChictR & CRiS & RPCEC & EU CTR & DRKS & IRCT & ISRCTN & NTR & PACTR & SLCTR \\
\hline \multicolumn{15}{|l|}{ Multilingualization } \\
\hline Multilingualization of website & Yes & No & No & Yes & Yes & Yes & Yes & No & Yes & Yes & Yes & No & No & No \\
\hline $\begin{array}{l}\text { Multilingualization of contact } \\
\text { information }\end{array}$ & Yes & - & - & No & Yes & Yes & Yes & - & Yes & Yes & No & Yes & No & No \\
\hline $\begin{array}{l}\text { Multilingualization of clinical trial } \\
\text { information }\end{array}$ & Yes & - & - & Yes & Yes & Yes & Yes & - & Yes & Yes & No & No & No & No \\
\hline \multicolumn{15}{|l|}{ Navigation } \\
\hline $\begin{array}{l}\text { Includes 'clinical trial' in the global } \\
\text { navigation }\end{array}$ & No & Yes & Yes & Yes & Yes & No & No & No & No & No & No & No & No & No \\
\hline $\begin{array}{l}\text { Global navigation includes the } \\
\text { roles 'patient' and 'health } \\
\text { professionals' }\end{array}$ & No & Partly & No & No & No & No & No & No & No & No & No & No & No & No \\
\hline $\begin{array}{l}\text { Minimum number of clicks to } \\
\text { access clinical trial information } \\
\text { (patient) }\end{array}$ & 1 & 1 & - & - & - & No & No & No & No & No & No & No & No & No \\
\hline $\begin{array}{l}\text { Minimum number of clicks to access } \\
\text { clinical trial information (health } \\
\text { professional) }\end{array}$ & - & 1 & - & - & - & No & No & No & No & No & No & No & No & No \\
\hline $\begin{array}{l}\text { Minimum number of clicks to } \\
\text { access clinical trial information } \\
\text { (practitioner) }\end{array}$ & - & 1 & - & - & - & No & No & No & No & No & No & No & No & No \\
\hline $\begin{array}{l}\text { Easy access to clinical trial } \\
\text { information }\end{array}$ & Yes & Yes & - & - & - & No & - & Partly & - & - & Yes & - & - & - \\
\hline Breadcrumb navigation & Yes & Yes & No & Yes & No & No & Yes & No & No & No & No & No & No & No \\
\hline \multicolumn{15}{|l|}{ Search } \\
\hline Search for clinical trial information & Yes & Yes & Yes & Yes & Yes & Yes & Yes & Yes & Yes & Yes & Yes & Yes & Yes & Yes \\
\hline $\begin{array}{l}\text { Optional search function for } \\
\text { clinical trial information }\end{array}$ & $\begin{array}{l}\text { Keywords, } \\
\text { several } \\
\text { conditions }\end{array}$ & $\begin{array}{l}\text { Keywords, } \\
\text { several } \\
\text { conditions }\end{array}$ & $\begin{array}{l}\text { Several } \\
\text { conditions }\end{array}$ & $\begin{array}{l}\text { Keywords, } \\
\text { several } \\
\text { conditions }\end{array}$ & $\begin{array}{l}\text { Several } \\
\text { conditions }\end{array}$ & $\begin{array}{l}\text { Several } \\
\text { conditions }\end{array}$ & $\begin{array}{l}\text { Several } \\
\text { conditions }\end{array}$ & $\begin{array}{l}\text { Keywords, } \\
\text { several } \\
\text { conditions }\end{array}$ & $\begin{array}{l}\text { Several } \\
\text { conditions }\end{array}$ & $\begin{array}{l}\text { Several } \\
\text { conditions }\end{array}$ & Keywords & $\begin{array}{l}\text { Several } \\
\text { conditions }\end{array}$ & $\begin{array}{l}\text { Keywords, } \\
\text { several } \\
\text { conditions }\end{array}$ & $\begin{array}{l}\text { Several } \\
\text { conditions }\end{array}$ \\
\hline Display contents of search results & 6 items & 4 items & 6 items & 4 items & 4 items & 2 items & 1 item & 13 items & 3 items & 1 item & 4 items & 3 items & 4 items & 1 item \\
\hline $\begin{array}{l}\text { Overview display of search results } \\
\text { for patients }\end{array}$ & No & No & Yes & No & No & No & No & No & No & Yes & No & No & No & No \\
\hline $\begin{array}{l}\text { Clinical trial search for each specific } \\
\text { disease area }\end{array}$ & No & No & No & No & No & No & No & No & No & No & No & No & No & No \\
\hline $\begin{array}{l}\text { Information regarding past clinical } \\
\text { trials }\end{array}$ & Yes & Yes & Yes & Yes & Yes & Yes & Yes & Yes & Yes & Yes & Yes & Yes & Yes & Yes \\
\hline $\begin{array}{l}\text { Information regarding clinical trials } \\
\text { conducted in other facilities }\end{array}$ & Yes & Yes & Yes & Yes & Yes & Yes & Yes & Yes & Yes & Yes & Yes & Yes & Yes & Yes \\
\hline Keyword shortcut to search & No & No & No & No & No & Yes & No & No & No & No & No & No & No & No \\
\hline
\end{tabular}


Table 4 Website function, communication, design and accessibility

\begin{tabular}{|c|c|c|c|c|c|c|c|c|c|c|c|c|c|c|}
\hline Assessment item & JPRN & CT.gov & ANZCTR & ReBec & ChictR & CRiS & RPCEC & EU CTR & DRKS & IRCT & ISRCTN & NTR & PACTR & SLCTR \\
\hline \multicolumn{15}{|l|}{ Function } \\
\hline $\begin{array}{l}\text { Clinical trial data output } \\
\text { (RSS, XML or CSV) }\end{array}$ & No & Yes & Yes & Yes & No & Yes & No & Yes & Yes & No & No & No & No & No \\
\hline $\begin{array}{l}\text { Function to evaluate the } \\
\text { content }\end{array}$ & No & No & No & No & No & No & No & No & No & No & No & No & No & No \\
\hline $\begin{array}{l}\text { Function to submit } \\
\text { opinions and requests }\end{array}$ & Partly & Yes & Yes & No & No & No & No & Yes & Yes & No & Partly & No & Yes & No \\
\hline \multicolumn{15}{|l|}{ Communication } \\
\hline Use of social media & No & No & No & No & No & No & No & No & No & No & Yes & No & No & No \\
\hline Email address & Partly & No & Yes & Yes & Yes & No & Yes & Yes & Yes & Yes & Yes & Yes & Yes & Yes \\
\hline Phone number & Yes & No & Yes & Yes & Yes & Yes & Yes & No & Yes & Yes & Yes & No & Yes & Yes \\
\hline Fax number & Yes & No & Yes & No & Yes & Yes & No & No & Yes & Yes & Yes & No & Yes & Yes \\
\hline Transportation guide & Yes & No & No & No & No & - & No & No & No & No & No & No & No & No \\
\hline Inquiry form & Yes & Yes & Yes & Yes & No & - & Yes & No & Yes & Yes & No & No & Yes & No \\
\hline Contact for each purpose & Yes & No & No & No & No & - & No & No & No & No & No & No & No & No \\
\hline Alternate contact method & No & No & No & No & No & No & No & No & No & No & No & No & No & No \\
\hline $\begin{array}{l}\text { How to apply for the } \\
\text { clinical trial }\end{array}$ & No & Yes & No & No & No & No & No & No & No & No & No & No & No & No \\
\hline $\begin{array}{l}\text { Apply for the clinical } \\
\text { trial from the website }\end{array}$ & No & No & No & No & No & No & No & No & No & No & No & No & No & No \\
\hline \multicolumn{15}{|l|}{ Design } \\
\hline $\begin{array}{l}\text { Website compatible with } \\
\text { smartphones }\end{array}$ & No & No & No & No & No & No & No & No & No & No & No & No & No & No \\
\hline $\begin{array}{l}\text { Website compatible with } \\
\text { feature phones }\end{array}$ & No & No & No & No & No & No & No & No & No & No & No & No & No & No \\
\hline $\begin{array}{l}\text { Website compatible with } \\
\text { tablets }\end{array}$ & No & No & No & No & No & No & No & No & No & No & No & No & No & No \\
\hline \multicolumn{15}{|l|}{ Accessibility } \\
\hline Font size & No & No & No & No & No & No & Yes & No & Yes & No & No & No & Yes & No \\
\hline Images with alt attribute & Yes & Yes & Yes & Yes & Partly & Partly & Yes & Yes & Yes & No & No & Partly & Partly & No \\
\hline $\begin{array}{l}\text { Elimination of layout } \\
\text { by }<\text { table }>\text { tag }\end{array}$ & Yes & Yes & Yes & Yes & Yes & Yes & Yes & No & Yes & No & No & No & Yes & No \\
\hline
\end{tabular}

'No' encompasses 'not provided', 'no description' and 'no distinction'. A dash (-) indicates that the response is summarized in the answer of another item or could not be evaluated.

CSV, comma-separated values; RSS, RDF site summary; XML, extensible markup language.

allows users to jump to other pages in the hierarchy via links, making the website easier to navigate. We assessed each website in terms of what was displayed in the banner area on the homepage and the global navigation system by which users can move around the site. Four websites included 'clinical trial' in their global navigation options, four websites facilitated easy access to clinical trial information, and four websites had breadcrumb navigation features. The definition of 'easy access' followed NCI recommendation 7 in the Website Usability Test Report [10]: 'Redesign the home page to reduce the amount of text and make links to important topics on third-level pages visible'.

As CT.gov was the only website to offer a separate page for each user type, it was also the only registry to which certain items applied: 'Global navigation includes the roles "patient" and "health professionals", and 'Minimum number of clicks to access clinical trial information'.

All registry websites had a search function for clinical trial information and displayed information on past clinical trials and trials conducted in other facilities. A few websites had functions such as an overview display of search results for patients, and keyword shortcuts for searching (Table 3).

\section{Website function, communication, design and accessibility Website function and communication}

Six websites had an output function for clinical trial data: data could be retrieved in RSS (RDF site summary), XML (extensible markup language) or CSV (comma-separated 
values) format. Seven websites had a function for users to submit opinions and requests. However, no website had a function to allow users to evaluate the website content. The International Standard Randomised Controlled Trial Number Register (ISRCTN.org) site [11] was the only website that used social media (Twitter).

\section{Website design and accessibility}

None of the websites were designed to be natively compatible with smartphones, feature phones or tablets. Three websites included features to adjust the font size. The aim of the JPRN portal site is to be accessible to all people, including disabled people. The following items were included in the category for accessibility.

Alt attributes, cascading style sheets (CSS) and tableless design are relevant for accessibility. The alt attribute is the alternative text attached to an image. For users who need a voice browser, it is the string that can be read by a text-to-speech browser and that is displayed when the image is not found. Six websites attached an alt attribute almost perfectly; however, images were not widely used on three websites. Use of a CSS layout (used instead of a table layout) along with the $<$ table $>$ tag to present data as a table, avoids the use of tables as a basis for the entire webpage layout (which was a feature of earlier web browsers). Without this feature, for users who need a voice browser, it is not possible to distribute the contents accurately because the structure of the content is dependent on appearance. The layouts of seven websites used CSS instead of the table layout using the $<$ table $>$ tag (Table 4 )

\section{Discussion}

The results of this assessment demonstrate that few websites (particularly those in a native language other than English) were easily accessible by patients and the general public for locating information on clinical trials. Currently, the NCI [12] website allows users to search for clinical cancer trials using data imported from CT. gov. Before CT.gov began to administer the website, $\mathrm{NCI}$ had its own original database of clinical trials from the 1970s. At that time, there were two versions of trial descriptions, one for health professionals and one for patients. The patient version displayed optional information on the purpose, eligibility, treatment/intervention, lead organizations, trial sites and contacts. Moreover, the current NCI website is a very good example of efforts to create and improve a website for patients and the general public. Dear et al. pointed out that the most important additional item for website users was the lay summary $[13,14]$. With an overview display of clinical trial search results, patients and the public can easily understand the contents and whether particular clinical trials are associated with their disease. In addition, a lay summary of the information may help in their decision-making regarding which clinical trials to join [15].

Several problems with clinical trial registry websites that we encountered were identified by the Clinical Trial Activation Committee [5]. One issue is that people cannot find information on the clinical research or trials related to their own diseases, e.g., how many clinical trials are being conducted or if they are taking place at a nearby location. It is also a problem that the total number of clinical trials that have been conducted in Japan cannot be calculated (some clinical trials conducted in Japan were registered in overseas registries). Grobler et al. pointed out the problem of duplicate trial registration $[15,16]$. Some organizations have already identified this as an important issue, and several (e.g. CT. gov and ICTRP) have made efforts to reduce duplicate registrations by using unique identifiers. To avoid publication bias and selective reporting, the WHO Trial Registration Data Set comprising 20 data elements has been approved by the International Committee of Medical Journal Editors [9,17,18]. However, only a few items pertain to those patients and individuals in the general population who are asking for specific and prioritized information. Some of the requested data elements may be unavailable to them. Further investigation is needed to determine which information is most desired by patients and the general public.

We have not yet had much opportunity to ascertain user opinions about the JPRN portal. Despite limited personnel and budget, there is a need to continuously improve the website and to evaluate the site contents by methods such as satisfaction surveys. CT.gov and NCI conduct a standard survey to address this need: the American Customer Satisfaction Index Online Consumer Survey [19]; however, other surveys regarding website usability and internet user satisfaction were not found in this study. To improve a website, at the very least, current information is required on how users access the website and use the search function. Access log analysis is one way to understand the behavior of internet information seekers $[20,21]$. Another option is the use of website evaluations that are accessible and userfriendly and therefore provide a good opportunity for receiving feedback directly from users. However, feedback should be verified against the content provided and the actual information requested by users [22-24]. Improved accessibility of websites is likely to make a good impression on all users.

CT.gov's clinical trials database is the largest of all the organizations assessed (excluding ICTRP), and it has a long history of system operation and system management [25]. Clinical trial registration is required by federal law in the United States [26-29] and by the 
European Medicines Agency [30] in the EU. However, in Japan, there is currently no such legislation. If such legislation were introduced, it might be possible for the JPRN to create a common format or dataset, and the addition of common data elements for clinical trial registration (excluding the 20 minimum data elements proposed by WHO [31]) could proceed and be harmonized smoothly. In addition, the current JPRN website does not offer a means for clinical trial data output. This limits distribution to the public, except via the ICTRP, because there is no authentication of the data provided by the three organizations. In addition, there are a few unique problems with the JPRN portal site: it is not linked to an adequate number of hospitals or associations; few of the general public know of its existence or how to access it; and patients and the public are not aware of the useful information it contains [32,33]. It is possible that the National Institute of Public Health will begin to play a role in the management and distribution of clinical research and clinical trial information in Japan. There are still many challenges for organizations to overcome, including the distribution of clinical trial information to patients and their families [15,34,35]. A big challenge is the format of the data in JPRN: a different Japanese format and system are used by each of the three organizations. Therefore, it is necessary to reform the legal system with respect to new data input into the portal; it should be mandated that lay terms be provided at registration to enable patients and the general public to understand them more easily.

\section{Conclusions}

In this study, the content and the characteristics of the online registry systems were found to be different for each organization. We confirmed that there were few websites that provided useful clinical trial information to patients and the general public. It is likely that the number of years of website operation, the amount of integrated data collected on clinical trials, and regional characteristics and resources (personnel and budget) differ by organization and thus affect their content and design. Moreover, concerning the dissemination of their services to patients and the public, we discovered room for improvement in the JPRN content and website systems. It follows that there may be other organizations that have similar challenges.

The distribution of clinical trial information to interested parties continues to be a challenge for WHO primary registries. Recommendations to improve the content and functions of these registries (including the JPRN) can be made based on advanced versions of other current websites, specifically, CT.gov and the NCI website.

\section{Abbreviations}

ANZCTR: Australian New Zealand Clinical Trials Registry; ChiCTR: Chinese Clinical Trial Registry; CSS: cascading style sheets; CRiS: Clinical Research
Information Service; CT.gov: ClinicalTrials.gov; DRKS: German Clinical Trials Register; EU-CTR: EU Clinical Trials Register; ICTRP: International Clinical Trials Registry Platform; IRB: institutional review board; IRCT: Iranian Registry of Clinical Trials; ISRCTN: International Standard Randomised Controlled Trial Number Register; JPRN: Japan Primary Registries Network; MHLW: Ministry of Health, Labour and Welfare; NCl: National Cancer Institute; NTR: Netherlands National Trial Register; PACTR: Pan African Clinical Trial Registry; ReBec: Brazilian Clinical Trials Registry; RPCEC: Cuban Public Registry of Clinical Trials; SLCTR: Sri Lanka Clinical Trials Registry; WHO: World Health Organization.

\section{Competing interests}

The authors declare that they have no competing interests.

\section{Authors' contributions}

DO contributed to the conceptualization, statistical analyses, interpretation of results and the first draft of the manuscript. KT contributed to the interpretation of results and the preparation of the final manuscript. HS contributed to the conceptualization, interpretation of results and the preparation of the final manuscript. All authors read and approved the final manuscript.

\section{Acknowledgements}

We gratefully acknowledge the assistance received from K. Yanagida, web designer and developer. This study was supported by a Health Labour Sciences Research Grant (Practical research on medical technology, clinical research promoting a research project) 2012-2013 (H24 - Clinical researchgeneral-002) from the Ministry of Health, Labour and Welfare, Japan.

\section{Author details}

'Department of Health Policy and Technology Assessment, National Institute of Public Health, 2-3-6 Minami, Wako, Saitama 351-0197, Japan. ²Department of Biostatistics, Nagoya University Graduate School of Medicine, Nagoya, Japan.

Received: 31 December 2013 Accepted: 17 October 2014

Published: 5 November 2014

\section{References}

1. National Institute of Public Health, Clinical Trials Search. [http://rctportal.niph.go.jp/en/index]

2. University Hospital Medical Information Network (UMIN). [http://www.umin.ac.jp/ctr/]

3. Japan Pharmaceutical Information Center, Clinical Trials Information (JapicCTI). [http://www.japic.or.jp/]

4. Japan Medical Association, Center for Clinical Trials (JMACCT). [http://www.jmacct.med.or.jp/en/]

5. Proceedings of the Fourth Clinical Research/Trial Activation Study Group in the Ministry of Health, Labour and Welfare: 2011 December 7 (in Japanese). [http://www.mhlw.go.jp/stf/shingi/2r9852000001zf1q.html]

6. Ministry of Health, Labour and Welfare: Clinical research/trial activation five-year plan. 2012 (in Japanese). [http://www.mhlw.go.jp/topics/ bukyoku/isei/chiken/dl/121025_3.pdf]

7. The Association of the British Pharmaceutical Industry: Best practice model for the disclosure of results and transparent information on clinical trials. 2008, [http://www.abpi.org.uk/our-work/library/guidelines/Pages/bestpractice-model.aspx]

8. US National Institutes of Health, ClinicalTrials.gov. [http://clinicaltrials.gov/]

9. The World Health Organization, international clinical trials registry platform (ICTRP). [http://www.who.int/ictrp/en/]

10. National Cancer Institute: International Clinical Trials Portal Website Usability Test: Report of Findings and Recommendations. Rockville, MD: Office of Communications and Education; 2011.

11. Current Controlled Trials, International Standard Randomised Controlled Trial Number Register (ISRCTN). [http://www.controlled-trials.com/]

12. US National Institutes of Health, National Cancer Institute (NCI). [http://www.cancer.gov/]

13. Dear R, Barratt A, Askie L, McGeechan K, Arora S, Crossing S, Currow D, Tattersall M: Adding value to clinical trial registries: insights from Australian Cancer Trials Online, a website for consumers. Clin Trials 2011, 8:70-76. 
14. Dear RF, Barratt AL, Crossing S, Butow PN, Hanson S, Tattersall MH: Consumer input into research: the Australian Cancer Trials website. Health Res Policy Syst 2011, 9:30

15. Faure H, Hrynaszkiewicz I: The ISRCTN Register: achievements and challenges 8 years on. J Evid Based Med 2011, 4:188-192.

16. Grobler L, Siegfried N, Askie L, Hooft L, Tharyan P, Antes G: National and multinational prospective trial registers. Lancet 2008, 372:1201-1202.

17. DeAngelis CD, Drazen JM, Frizelle FA, Haug C, Hoey J, Horton R, Kotzin S, Laine C, Marusic A, Overbeke AJ, Schroeder TV, Sox HC, Van Der Weyden MB, International Committee of Medical Journal Editors: Clinical trial registration: a statement from the International Committee of Medical Journal Editors. JAMA 2004, 292:1363-1364.

18. Askie $L$, Ghersi D, Simes J: Prospective registration of clinical trials. Aust $J$ Physiother 2006, 52:237-239.

19. The American Customer Satisfaction Index (ACSI). [http://www.theacsi. org/the-american-customer-satisfaction-index]

20. Wallwiener M, Wallwiener CW, Brucker SY, Hartkopf AD, Fehm TN, Kansy JK: The Brustkrebs-Studien.de website for breast cancer patients: user acceptance of a German internet portal offering information on the disease and treatment options, and a clinical trials matching service. BMC Cancer 2010, 10:663.

21. Patel CO, Garg V, Khan SA: What do patients search for when seeking clinical trial information online? AMIA Annu Symp Proc 2010, 597-601.

22. Eysenbach $G$, Köhler $C$ : How do consumers search for and appraise health information on the world wide web? Qualitative study using focus groups, usability tests, and in-depth interviews. BMJ 2002, 324:573-577.

23. Grama LM, Beckwith M, Bittinger W, Blais D, Lollar C, Middleswarth A, Noone M, Price D, Quint-Kasner S, Shields V, Wright LW: The role of user input in shaping online information from the National Cancer Institute. J Med Internet Res 2005, 7:e25.

24. Peterson G, Aslani P, Williams KA: How do consumers search for and appraise information on medicines on the Internet? A qualitative study using focus groups. J Med Internet Res 2003, 5:e33.

25. Califf RM, Zarin DA, Kramer JM, Sherman RE, Aberle LH, Tasneem A: Characteristics of clinical trials registered in ClinicalTrials.gov, 2007-2010. JAMA 2012, 307:1838-1847.

26. Zarin DA, Keselman A: Registering a clinical trial in ClinicalTrials.gov. Chest 2007, 131:909-912

27. Tse T, Williams RJ, Zarin DA: Reporting 'basic results' in ClinicalTrials.gov. Chest 2009, 136:295-303.

28. Tse T, Williams RJ, Zarin DA: Update on registration of clinical trials in ClinicalTrials.gov. Chest 2009, 136:304-305.

29. Zarin DA, Tse T, Williams RJ, Califf RM, Ide NC: The ClinicalTrials.gov results database - update and key issues. N Engl J Med 2011, 364:852-860.

30. European Medicines Agency, EU Clinical Trials Register. [https://www. clinicaltrialsregister.eu/]

31. WHO Trial Registration Data Set (Version 1.2.1). [http://www.who.int/ictrp/ network/trds/en/]

32. McCabe S: Open access to trials register. PLoS Med 2005, 2:e49

33. Mosconi P, Roberto A: Open-access clinical trial registries: the Italian scenario. Trials 2012, 13:194.

34. Askie LM: Australian New Zealand Clinical Trials Registry: history and growth. J Evid Based Med 2011, 4:185-187.

35. Hasselblatt $H$, Dreier G, Antes G, Schumacher M: The German Clinical Trials Register: challenges and chances of implementing a bilingual registry. J Evid Based Med 2009, 2:36-40

doi:10.1186/1745-6215-15-428

Cite this article as: Ogino et al:: Characteristics of clinical trial websites: information distribution between ClinicalTrials.gov and 13 primary registries in the WHO registry network. Trials 2014 15:428.

\section{Submit your next manuscript to BioMed Central and take full advantage of:}

- Convenient online submission

- Thorough peer review

- No space constraints or color figure charges

- Immediate publication on acceptance

- Inclusion in PubMed, CAS, Scopus and Google Scholar

- Research which is freely available for redistribution 